ARCHIVO ESPAÑOL DE ARTE, XCIII, 369

ENERO-MARZO 2020, pp. 55-63

ISSN: 0004-0428, eISSN: 1988-8511

https://doi.org/10.3989/aearte.2020.04

\title{
VARIA
}

\section{UNA ATRIBUCIÓN A JUAN DE JUNI EN EL BODE MUSEUM*}

\author{
Manuel Arias Martínez 1 \\ Museo Nacional de Escultura de Valladolid \\ MARÍA LÓPEZ-FANJUl y DíEZ DEL CORRAL ${ }^{2}$ \\ Bode-Museum, Staatliche Museen zu Berlin
}

\begin{abstract}
Este artículo está dedicado a estudiar un relieve en terracota conservado en el Bode-Museum de Berlin, atribuyéndolo al escultor Juan de Juni.

Palabras clave: Juan de Juni; Bode-Museum; Staatliche Museen zu Berlin; Wilhelm von Bode.
\end{abstract}

\section{AN ATTRIBUTION TO JUAN DE JUNI IN THE BODE MUSEUM}

This article is devoted to the study of a terracotta relief preserved in the Bode-Museum in Berlin and to its attribution to the sculptor Juan de Juni.

Key words: Juan de Juni; Bode-Museum; Staatliche Museen zu Berlin; Wilhelm von Bode.

Cómo citar este artículo / Citation: Arias Martínez, Manuel / López-Fanjul y Díez del Corral, María (2020): "Una atribución a Juan de Juni en el Bode Museum”. En: Archivo Español de Arte, vol. 93, núm. 369, Madrid, pp. 55-63. https://doi.org/10.3989/aearte.2020.04.

En el año 1912 el historiador Wilhelm Bode (1845-1929), Director General de los actuales Staatliche Museen zu Berlin (Museos Nacionales de Berlín) ${ }^{3}$, compró durante un viaje a Venecia un pequeño relieve en terracota de la Virgen con el Niño y San Juanito. Estaba convencido de haber encontrado un boceto original de Donatello (1386-1466) y para celebrarlo, quiso fotografiarse con él en el único retrato que se le conoce junto a una obra del artista florentino [figs. 1 y 2$]^{4}$.

* Los autores de este artículo agradecen profundamente al Dr. Neville Rowley el haberles llamado la atención sobre este relieve.

El estudio para este artículo ha sido llevado a cabo gracias al proyecto MINECO HAR2017-83330-P "Cultura y comunicación de las élites aristocráticas ibéricas del Siglo de Oro: signos de reconocimiento y formas de vida".

1 manuel.arias@cultura.gob.es / ORCID iD: http://orcid.org/0000-0002-5363-3368.

2 m.lopez-fanjul@smb.spk-berlin.de / ORCID iD: http://orcid.org/0000-0002-5546-7105.

${ }^{3}$ Los 15 museos y 4 institutos de investigación que hoy en día se extienden en la Isla de los Museos y en las zonas de Charlottenburg, Dahlem y Kulturforum. Wilhelm Bode fue ennoblecido en 1914, añadiendo como consecuencia la partícula "von" a su apellido y pasando a llamarse a partir de entonces Wilhelm von Bode.

${ }^{4}$ Inv. M 113; 27,5 x 20 cm; barro cocido. Bode, 1997: 344. 


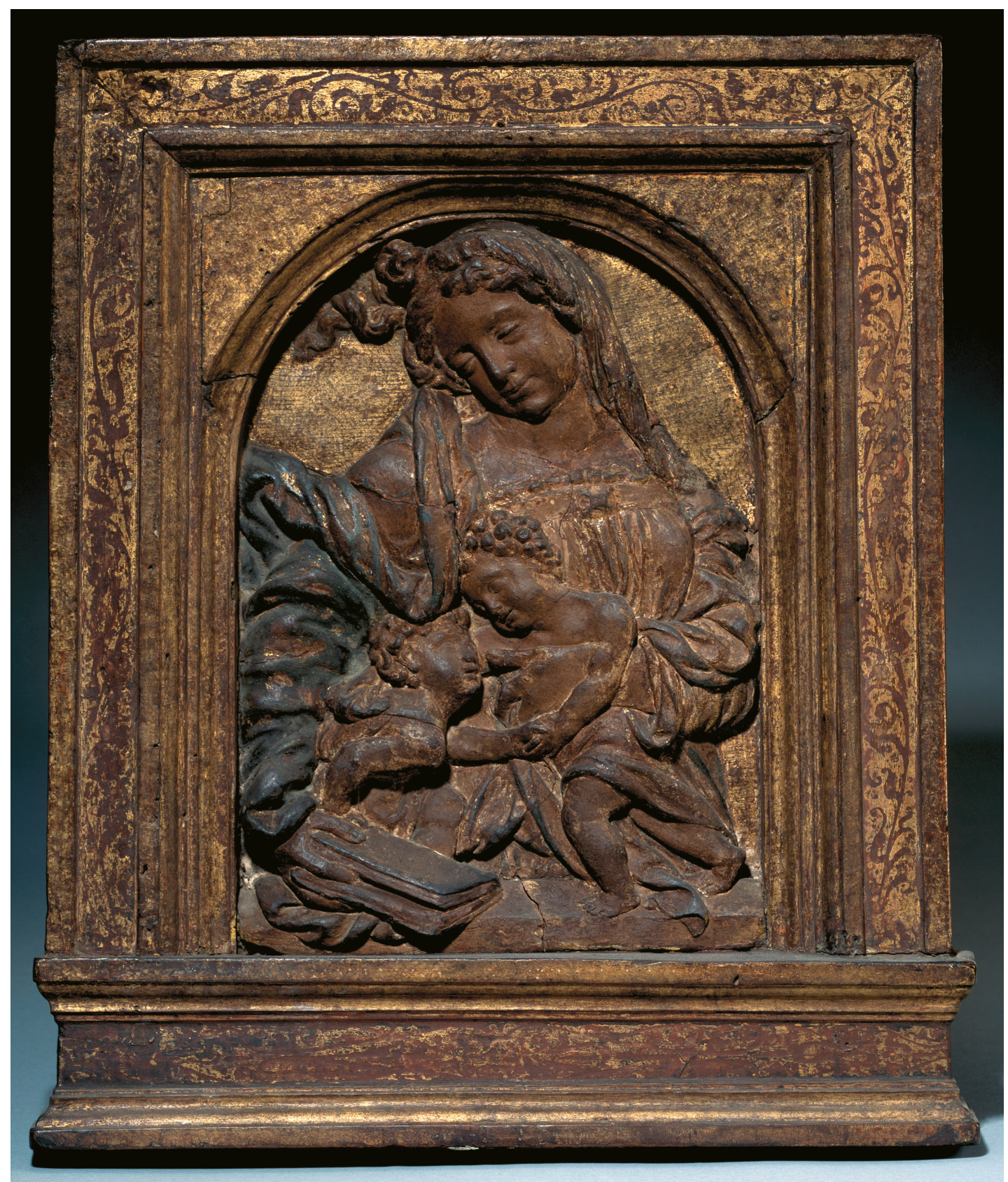

Fig. 1. Juan de Juni, Virgen Bode, ca. 1560. (C) Staatliche Museen zu Berlin/Volker Schneider. 
Fig. 2. Wilhelm von Bode, ca. 1912. (C) Zentralarchiv. Staatliche Museen zu Berlin.

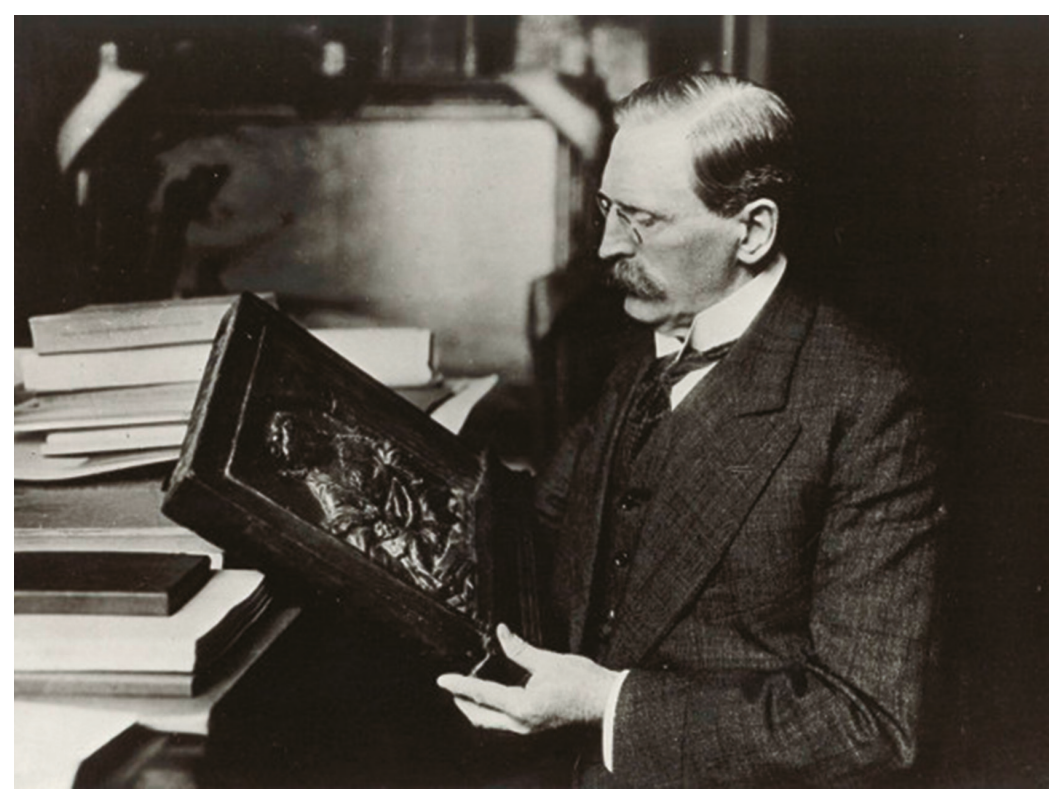

La pieza pasó a partir de entonces a formar parte de la extensa colección de obras de Donatello en Berlín - hoy en día considerada la más importante fuera de Italia - y a exponerse en la famosa Isla de los Museos. Más concretamente en el Kaiser-Friedrich-Museum (Museo del Emperador Federico), que en 1956 sería rebautizado bajo el nombre de su alma mater como el Bode Museum.

El estudio de este relieve ha permitido su atribución al escultor Juan de Juni (1507-1577). Su descubrimiento ejemplariza además la labor de búsqueda e investigación de sus propias colecciones en la que los museos berlineses siguen inmersos tras la caída del Muro de Berlín.

\section{El Bode Museum}

El futuro Bode Museum estaba llamado a ser un hito en la historia de la museografía europea. A diferencia de otros grandes museos metropolitanos, en los que a principios del siglo XX se revalorizaba la pintura frente a las demás artes, se equipararon aquí todos los géneros y las salas se organizaron cronológica y geográficamente. Wilhelm Bode ideó un edificio de nueva planta en el que exponer conjuntamente pintura, escultura, artes decorativas, y elementos arquitectónicos. Famosa es su sala central en forma de basílica, en la que se unen las cuatro artes. Contrario además a la exposición de las obras aisladas de su contexto, Bode recreó ambientes históricos, en un tipo de presentación expositiva que tuvo amplia acogida y largo recorrido especialmente en los museos americanos 5 .

Inaugurado en 1904, el Kaiser-Friedrich-Museum fue el cuarto de los cinco museos construídos en la Isla berlinesa bajo el apelativo común de los Königlichen Museen (Museos Reales). Erigidos en la época de máximo apogeo del II Imperio alemán, su historia estuvo sin embargo marcada por las mayores guerras de la historia europea. La Guerra de los Treinta Años (16181648) destruyó su núcleo de origen, la Kunstkamer del Kurfürst Joaquín II de Brandenburgo. Tras la reconstrucción de las colecciones en los siglos posteriores, la I Guerra Mundial acabo con su patrocinio real para convertirlos en patrimonio estatal, pasando a denominarse Staatliche $\mathrm{Mu}-$ seen. Y finalmente, la II Guerra Mundial cambiaría radicalmente el destino de la Isla de los

5 Chapuis, 2006: 143-176. 
Museos, destruyendo gran parte de su colección y edificios. Más de un tercio de las obras se perdieron, incluso muchas de las más importantes, qué se creían a buen recaudo del peligro de las bombas, guardadas en minas y en el conocido como Flakbunker Friedrichshain a las afueras de Berlín.

En los días de confusión que siguieron al fin de la Guerra, el búnker ardió en al menos dos ocasiones y fue objeto de constantes robos. Poco, o más bien casi nada, se pudo recuperar de lo guardado en él y a día de hoy se desconoce el paradero de gran parte de las obras que albergaba, incluidas obras maestras de Goya, Murillo, Ribera, Alonso Cano y Zurbarán ${ }^{6}$. El resto de la colección berlinesa permaneció separada durante la ocupación soviética y la Guerra Fría, y su abrupto término, con la inesperada caída del Muro de Berlín en 1989, provocó que los Museos tuvieran que tomar trascendentales decisiones museológicas en demasiado poco tiempo.

En la década de 1950-1960, un gran centro cultural fue ideado en el Berlín occidental como contraposición a la Isla de los Museos del lado oriental: el conocido como "Foro de la cultura" (Kulturforum). A sus modernos edificios debían trasladarse las colecciones que tras la II Guerra habían quedado en el lado occidental y eran custodiadas temporalmente en el distrito berlinés de Dahlem. La caída del Muro sorprendió a los museos en la última fase de este proceso, que siguió adelante sin considerar las nuevas perspectivas culturales de una ciudad reunificada. En parte para poder asumir el sobrevenido trabajo de unir las colecciones, éstas se dividieron en géneros. Pero, lo que en un principio sólo parecía una solución temporal, motivada por la necesidad de reaccionar rápidamente a una situación política, económica y social completamente imprevista, terminó anclándose en la memoria colectiva. Así la pintura y las artes decorativas se expusieron respectivamente en la Gemäldegalerie y en el Kunstgewerbemuseum del Kulturforum. La colección de escultura, junto a las de numismática y arte bizantino, aguardaron almacenadas hasta que los trabajos de restauración del Bode Museum permitieron su reinaguración en el año 2006, donde hoy en día pueden visitarse.

1989 reunificó un país, pero también marcó la ruptura de una colección y el fin del "museo total" concebido por Wilhelm Bode. Fue el comienzo del mayor reto al que hoy en día siguen enfrentándose los museos de Berlín: la búsqueda, localización e identificación de sus colecciones perdidas. Incluida la española.

La colección de escultura española del Bode Museum aún no ha sido estudiada en profundidad y se desconoce el número total de obras que la integran. A día de hoy se han identificado sin embargo importantes piezas, entre otras, de Diego de Siloé, Juan de Valmaseda y Pedro Roldán, que ilustran el interés de Wilhelm Bode por la calidad artística, y que permiten definir el conjunto español cómo el más importante de Alemania.

\section{Juan de Juni y "La Virgen con el Niño y San Juanito"}

En su autobiografía, que sólo vería la luz postumamente por expreso deseo del autor, Wilhelm Bode relata con manifiesta alegría cómo, a pesar de la trombosis que le tuvo postrado durante seis meses, en 1912 viajó a Italia donde "he conseguido [...] la adquisición de dos modelos de Donatello con relieves de la Virgen"7. Sólo un año después de su compra, el relieve que nos ocupa fue oficialmente incluido en el catálogo de la colección de escultura como un boceto de Donatello ${ }^{8}$. Esta atribución pervivió durante los siguientes veinte años hasta que, tras la muerte de Bode, una nueva catalogación fue llevada a cabo y la obra pasó a ser considerada de mano de un seguidor de Jacopo Sansovino (1486-1570) ${ }^{9}$. Cómo consecuencia de la pérdida de una atribu-

\footnotetext{
${ }^{6}$ Staatliche Museen zu Berlin (1995). Chapuis / Kemperdick / Alexander / Kline / Pardoe / Staatliche Museen zu Berlin, 2015.

7 "Es geland mir [...] der Erwerbung von zwei Modellen Donatellos für Madonnenreliefs": Bode, 1997: 387. El segundo relieve al que se refiere es Inv. Nr. M88.

8 Schotmüller, 1913: 20.

9 Schotmüller, 1933: 185.
} 
ción concreta, la pieza se descolgó de las salas de exposición permanente para guardarse en los almacenes. Allí se quedó hasta la llegada de la II Guerra Mundial, tras la cual pasó a formar parte de la colección del Berlín occidental ${ }^{10}$.

El proyecto de búsqueda, estudio y exposición de las esculturas de Donatello que el Dr. Neville Rowley, ha llevado a cabo en los últimos años en el Bode-Museum ha permitido volver a estudiar el relieve ${ }^{11}$. A pesar de la carencia de material documental que lo certifique, la composición formal, la disposición de las figuras, el tratamiento de los volúmenes, su parecido a otras obras, y el material empleado fundamentan, cómo veremos a continuación, la atribución de la obra a Juan de Juni.

Juan de Juni nació alrededor del año 1507 en Borgoña e hispanizó el nombre de su ciudad de origen, Joigny, para utilizarlo cómo apellido tras llegar en torno a 1533 a Castilla, documentándose primero en León y Salamanca, para terminar por establecerse en la capital de facto de la corte, la ciudad de Valladolid ${ }^{12}$. Escultor y arquitecto de retablos, rápidamente se convirtió en uno de los artistas más importantes en la Castilla del siglo XVI, contemporáneo de la arrolladora figura de Alonso Berruguete y ejemplo de la influyente presencia del mundo centroeuropeo en la España de su tiempo. Formado en su país natal, desconocemos muchos aspectos de su periodo inicial ${ }^{13}$, pero sin duda y como delata su producción española, tuvo que estar muy vinculado con la excelente calidad de la escultura borgoñona cuya tradición lo convirtió en uno de los más hábiles artífices del siglo. A pesar de que Martín González diera por hecho que Juni tuvo que pasar por Italia, tal evidencia no está documentada y existe un cierto debate sobre el tema ${ }^{14}$. Lo cierto es que el conocimiento y la influencia de lo italiano en su producción no hacen necesario el viaje. Además de la circulación constante de estampas y modelos, a Francia llegaban artistas italianos que, como sucedió en el caso de Fontainebleau, imprimieron una lectura muy característica a aquel lenguaje, del que Juni también participa en su obra española. Esas influencias hacían que estuviera muy presente el magisterio de los grandes genios del Cinquecento y lógicamente, de maestros anteriores a los que se recurría como creadores de tipos, como sucede con della Quercia y sobre todo con Donatello. Influencias que traicionaron, incluso, la pericia de Wilhelm Bode. Pues la iconografía de la obra que nos ocupa (a partir de ahora Virgen Bode), es en gran parte el resultado de la evolución de caminos abiertos por Donatello en la primera mitad del siglo XV, que serían sin embargo personalísimamente reinterpretados por Juni.

En el centro de la composición de la Virgen Bode, María rodea con el brazo derecho a San Juanito mientras marca con el dedo índice la página de un libro y sostiene con la mano izquierda al Niño Jesús. Ambos Primos hacen ademán de abrazarse. Una composición que Juni resuelve de manera extraordinariamente similar en la Virgen del Rosario de León, que encargaba doña Catalina Pimentel, Condesa de Luna, en 1541 y que sabemos con certeza que estaba realizada en $1549^{15}$ [fig. 3]. En ambas piezas observamos dos de las características más personales de la

10 Schotmüller, 1933: 185.

11 El Prof. Dr. Francesco Caglioti y el Prof. Dr. Giancarlo Gentilini indicaron verbalmente por primera vez la posible atribución española de este relieve durante el congreso "Donatello und das verschwundene Museum", celebrado el 17 y el 18 de septiembre de 2015 en el Bode-Museum.

${ }^{12}$ La bibliografía sobre Juan de Juni es muy amplia en la historiografía española, desde el mundo de los tratadistas antiguos. Se han escrito diferentes trabajos específicos referidos a obras concretas o de carácter más global, pero la monografía dedicada al artista, que sigue siendo esencial para su conocimiento, es la que publicaba Martín González, 1974. Posteriormente, Fernández del Hoyo, 2012., ha puesto al día con claridad y rigor las novedades que se habían producido en el estudio del escultor desde 1974 no sólo en lo biográfico sino también en lo formal o en lo relacionado con las atribuciones, recopilando la bibliografía específica de cada una de las obras que forman su catálogo. Por ese motivo citaremos esta publicación cuando nos refiramos a piezas de Juni, lo que resultará más útil para el lector.

13 No obstante, ha habido algún intento de profundizar en su actividad previa a su llegada a España. Como ejemplo véase Peltier, 2006: 15-22.

${ }^{14}$ Una puesta al día sobre el tema en Fernández del Hoyo, 2012: 19-22.

15 Fernández del Hoyo, 2012:169-170. 


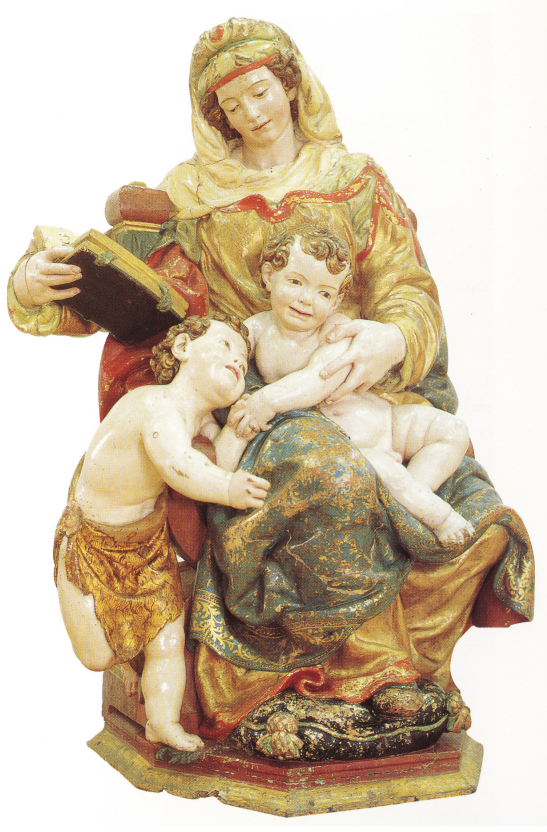

Fig. 3. Juan de Juni. Virgen del Rosario. Madera policromada. Iglesia parroquial de Santa Marina, León.

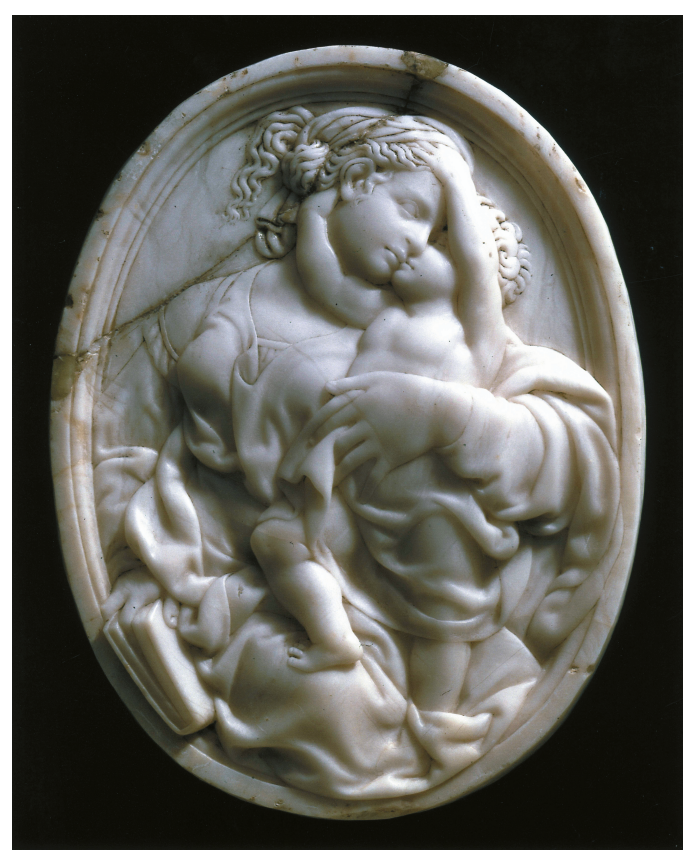

Fig. 4. Juan de Juni. Virgen con el Niño. Alabastro. Instituto Gómez Moreno, Granada. (C) Javier Algarra.

producción de Juni: la sensación de profundidad, conseguida a través del leve giro del cuerpo de la Virgen, y la inclinación hacia un lado de su cabeza. Especialmente similares son también la fisonomía de la Virgen, su rostro redondeado, las manos enlazadas de los Niños, el abrazo firme de la Madre a su Hijo y la manera en la que María sostiene el libro. Éste último gesto, aunque no exclusivo de Juni, también se encuentra en el pequeño y exquisito relieve representando a la Virgen con el Niño que se le ha atribuido sin discusión en el Instituto Gómez-Moreno de Granada $^{16}$ [fig. 4].

Con la placa granadina, la Virgen Bode también comparte la reconocida anticipación de Juni al lenguaje barroco: la composición se ordena en torno a una figura principal que ocupa casi la totalidad del espacio y los detalles captan la fugacidad temporal. En ambas Vírgenes una ráfaga de viento hace ondular el manto; en la de Berlín éste se eleva sobre el hombro derecho y en la de Granada se ahueca bajo el brazo izquierdo. En la primera, además, el cabello ensortijado vuela hacia la parte superior del rostro, como en la captación de un instante. Un gusto por la representación del movimiento que también aparece, por ejemplo, en el paño de pureza desanudado del Crucificado de Ciudad Rodrigo, hoy en el Museo Nacional de Escultura ${ }^{17}$.

La construcción compositiva es bastante común en la producción de Juni. El artista es un creador de estructuras que, aunque responden a planteamientos muy medidos, adapta a las necesidades iconográficas. Este modo de trabajar puede apreciarse si comparamos la Virgen Bode con la escultura que muestra a la Virgen con el Niño Jesús dormido de Becerril de Campos [fig. 5] y su versión en tamaño reducido del Museo Catedralicio de Tuy, que tanto Martín González como Fernández del Hoyo vinculan con una inspiración quattrocentesca ${ }^{18}$. En los tres casos, teniendo en cuenta que las últimas dos obras son de bulto redondo, estamos ante una estructura geométrica muy similar: del Niño dormido en el caso de la tipología de bulto, se pasaría al juego de Jesús y San Juanito en el caso del relieve. Además, las tres representaciones de la Virgen comparten el

\footnotetext{
16 Sánchez-Mesa Martín, 1992: 72, nº de catálogo 145. Placa de alabastro. 22 x $17 \mathrm{~cm}$.

17 Fernández del Hoyo, 2012: 141-143.

18 Fernández del Hoyo, 2012:171-172.
} 


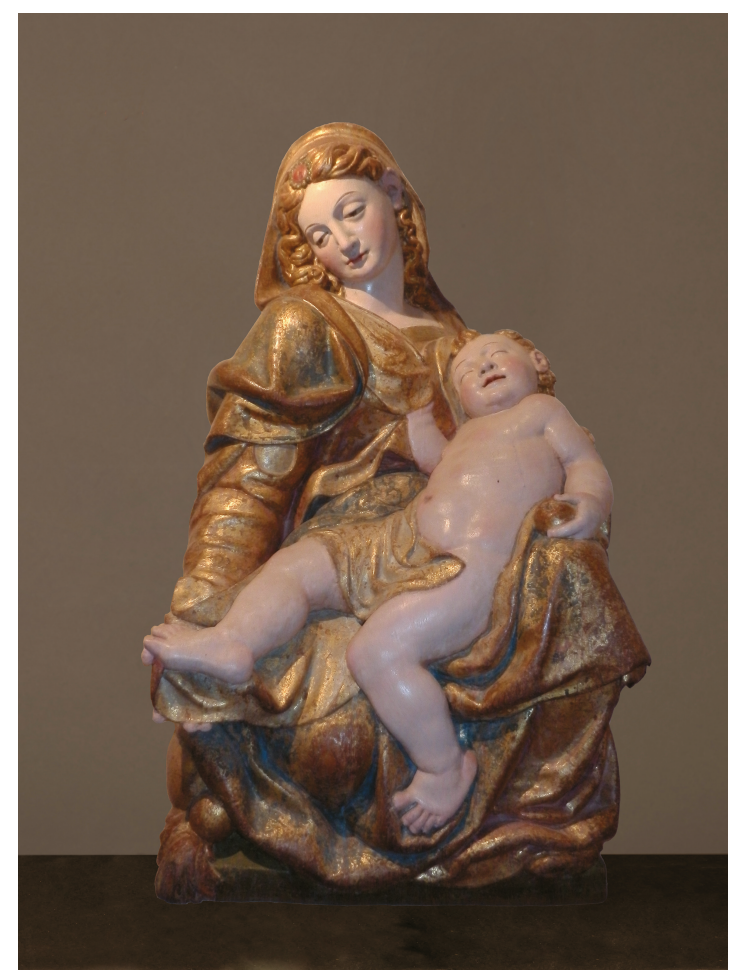

Fig. 5. Juan de Juni. Virgen con el Niño. Madera policromada. Museo parroquial de Becerril de Campos (Palencia).

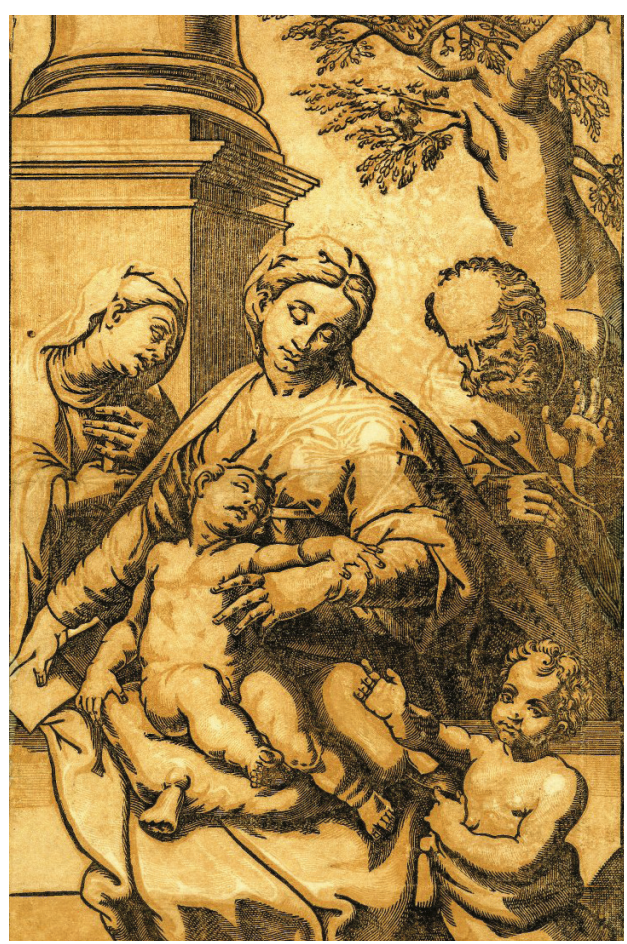

Fig. 6. Siguiendo a Marco Pino. Sagrada Familia con Santa Isabel y San Juanito. Grabado al claroscuro. British Museum, Londres. (C) The Trustees of the British. Museum 1859,0709.2364.

modo de inclinación de la cabeza, la misma manera de resolver los pliegues ondulados (de extraordinaria similitud especialmente sobre el hombro derecho) y la fisonomía - con un rostro ovalado de nariz recta, ojos caídos y mirada dulce. Esta repetición de detalles también la encontramos en el broche redondo que decora el escote de la Virgen; uno de los elementos decorativos más generalizados en sus figuras femeninas. La misma decoración se aprecia, por ejemplo, sujetando los mantos de la Santa Ana de la Catedral Nueva de Salamanca, de la Virgen en el conjunto del Santo Entierro del Museo Nacional de Escultura y de una de las tres Marías en la Piedad de la Catedral Vieja de Salamanca ${ }^{19}$.

Este modo de construcción, en el que un mismo tipo de esquema compositivo puede adaptarse a diferentes temas, lo toma Juni del rico mundo de las estampas. El escultor es capaz de mezclar elementos de procedencia diversa, como en un collage, para dar como resultado un producto nuevo que acusa el peso de esa influencia, pero que se convierte en algo realmente personal, con un rápido seguimiento por parte de sus colaboradores ${ }^{20}$. En esta ocasión podemos reparar en una posible fuente, sino literal al menos referencial y que puede ser útil planteada a manera de propuesta. Se trata de una estampa que presenta a la Sagrada Familia con Santa Isabel y San Juanito. La obra, cuya composición Bartsch relacionaba con Dosso Dossi o Correggio, se vincula hoy con Marco Pino da Siena [fig. 6] $]^{21}$. La posibilidad de invertir la escena, un ejer-

19 Fernández del Hoyo, 2012:176-177, 157-162, 156-157.

${ }^{20}$ Un ejemplo evidente del uso de las estampas y su adaptación por parte de Juni está en los relieves exteriores de San Marcos de León. Al respecto Arias Martínez, 2008: 9-34.

${ }^{21}$ Se conservan varios ejemplares en el British Museum, alguno de ellos con una inscripción en la que se señala a Correggio como "inventor". Se trata de una estampa xilográfica en claroscuro. Por ejemplo, la número $1837,0408.554$ 
cicio más que frecuente en el uso de este tipo de recursos, proporciona unas interesantes similitudes tanto con la Virgen Bode cómo con la de Becerril de Campos. En el caso de la segunda, el Niño se dispone incluso sobre un almohadón con borlones, que también aparece en la mencionada estampa.

Finalmente, el material —el barro cocido ${ }^{22}$ - si bien no abunda en la escultura española, sí que fue recurrentemente utilizado por Juni tanto en pequeñas composiciones cómo en piezas de gran tamaño; muy posiblemente cómo influencia de Jacopo della Quercia y de todo ese mundo de piedad doméstica que tanta fortuna tuvo en Italia. El pequeño formato de la Virgen Bode $(27,5$ x $20 \mathrm{~cm})$ sigue el de otras placas conocidas de la producción de Juni. De ellas se conservan bastantes ejemplos dedicados al tema de la Piedad, que ya llamaron la atención en 1724 a Palomino, en Valladolid, León, el Victoria and Albert Museum de Londres y Zaragoza ${ }^{23}$, que demuestran la fortuna de esta producción destinada a la devoción privada, y también en este caso un parentesco formal en los recursos empleados con la Virgen Bode. El fondo dorado, cómo una sutil imitación de mosaico a la romana, es también de influencia italiana. Donatello lo había empleado en la Madonna dei Cordai y en el púlpito de Prato, Rafael volvería a hacerlo en las Estancias Vaticanas. También se utilizaba en la Capella dei Priori en el Palazzo Vecchio florentino, sólo por añadir más ejemplos, y en España Alonso Berruguete hizo suya esta decoración como prueba patente de esa transmisión de influencias, en lo que se denominaban "labores musaicas" 24 .

El dominio del material le permite además a Juni producir esa sensación de telas ondulantes, visible en el modo de tratar las mangas y el velo de la Virgen Bode, a la vez que crea pliegues voluminosos de una minuciosidad completamente diferente a la de sus contemporáneos españoles. Ejemplo de ello son también el San Mateo conservado en el Museo de León ${ }^{25}$ o los excelentes grupos de San Jerónimo y El martirio de San Sebastián del convento de San Francisco en Medina de Rioseco ${ }^{26}$; auténtica cumbre de la plástica europea.

Pensando en las similitudes formales con obras como la mencionada de Becerril de Campos podríamos pensar en una fecha en torno a 1560, siguiendo la propuesta de María Antonia Fernández del Hoyo en relación con el parecido con las santas del retablo vallisoletano de Santa María de la Antigua ${ }^{27}$ a pesar de las dificultades que supone proponer una cronología certera.

El descubrimiento de la Virgen Bode quiere aportar una nueva propuesta para sumar al catálogo de Juni, enriqueciendo además nuestros conocimientos sobre su trabajo en barro, un material del que, por su fragilidad, se han conservado pocos ejemplos, para añadir nuevos matices sobre esta pequeña escultura dedicada a la devoción privada. Pero además, este feliz hallazgo viene a subrayar la fundamental necesidad de seguir investigando las colecciones españolas en territorio alemán donde con seguridad aún aguardan muchos más testimonios ${ }^{28}$.

22 Con restos de policromía y dorado.

${ }^{23}$ Fernández del Hoyo, 2012: 152-153. Respecto a la de Valladolid decía Palomino: "en la iglesia de San Martín de Valladolid hay una historiejita de barro cocido del Descendimiento de la Cruz, que la han vaciado algunos escultores por ser tan peregrina" Palomino, 1947: 830.

24 Arias Martínez, 2017: 203-206.

25 Fernández del Hoyo, 2012: 187-188.

${ }^{26}$ Fernández del Hoyo, 2012:184-186.

27 Fernández del Hoyo, 2012:171-172.

28 Sobre las colecciones españolas en museos alemanes ver, entre otros: Bode, 1885: 66-68. Weniger / Bucerius Kunst Forum / Gemäldegalerie Alte Meister / Szépmúvészeti Múzeum (eds.), 2005. Hellwig / Kurt, 2006. Weniger / Gemäldegalerie Alte Meister / Staatliche Kunstsammlungen Dresden (eds.), 2012. Español, 2013-2014:197-216. Carlos Varona / Hoffmann-Samland / Matilla / Hamburger Kunsthalle / Meadows Museum / Museo Nacional del Prado (eds.), 2014. López-Fanjul y Díez del Corral, 2014: 453-463. López-Fanjul y Díez del Corral / Gemäldegalerie / Hypo-Kulturstiftung (eds), 2016: 71-79. 


\section{BIBLIOGRAFÍA}

Arias Martínez, Manuel (2008): "Revisando a Juan de Juni en San Marcos de León. Fuentes y modelos". En: Boletín de la Real Academia de la Purísima Concepción de Valladolid, 43, Valladolid, pp. 9-34.

Arias Martínez, Manuel (2017): "Reinterpretando modelos". En: Arias Martínez, Manuel (comisario): Hijo del Laocoonte. Alonso Berruguete y la Antigüedad Pagana. Madrid: Secretaría General Técnica, Subdirección General de Documentación y Publicaciones.

Bode, Wilhelm von (1885): “Bemalte Holzbüste der schmerzensreichen Marian von Juan Martínez Montañés”. En: Jahrbuch der Königlich-Preußischen Kunstsammlungen, 6. Berlín: pp. 66-68.

Bode,Wilhelm von (1997): Mein Leben. Vol.I y II. Berlín: Nicolai.

Carlos Varona, María Cruz de / Hoffmann-Samland, Jens / Matilla, José Manuel / Hamburger Kunsthalle / Meadows Museum / Museo Nacional del Prado (eds.) (2014): Dibujos españoles en la Kunsthalle de Hamburgo. Madrid, Dallas y Hamburguer: Museo Nacional del Prado, Meadows Museum, Southern Methodist University y Hamburger Kunsthalle.

Chapuis, Julien (2006): "Bode und Amerika: eine komplexe Beziehung”. En: Jahrbuch Preußischer Kulturbesitz, 43, Berlín, pp. 143-176.

Chapuis, Julien / Kemperdick, Stephan / Alexander, Mark / Kline, Douglas / Pardoe, Lucelle / Staatliche Museen zu Berlin (2015): The lost museum: the Berlin painting and sculpture collections 70 years after World War II. Berlín y Petersberg: Skulpturensammlung und Museum für Byzantinische Kunst, Staatliche Museen zu Berlin y Michael Imhof Verlag.

Español, Francesca (2013-2014): "El sepulcre de Ramon de Cardona i Margarida de Bellera de Torà de Riubregós: el retorn des de la diàspora al seu escenari primitiu". En: Lambard. Estudis d'art medieval, XXV, Barcelona, pp. 197-216.

Fernández del Hoyo, María Antonia (2012): Juan de Juni, escultor. Valladolid: Universidad de Valladolid, Secretariado de Publicaciones e Intercambio Editorial.

Hellwig, Karin / Zeitler, Kurt (2006): El Greco kommentiert den Wettstreit der Künste. Eine Zeichnung in der Staatlichen Graphischen Sammlung München. München y Berlín: Deutscher Kunstverlag.

López-Fanjul y Díez del Corral, María (2014): “The Rediscovery of Francisco Pacheco's drawing of the "Adoration of the Cross". En: Master Drawings, 52, 4, New York, pp. 453-463.

López-Fanjul y Díez del Corral, María (2016): "Spanish baroque drawings and the collections of the Staatliche Museen zu Berlin”. En: López-Fanjul Díez del Corral, María / Gemäldegalerie / Hypo-Kulturstiftung (eds). El Siglo de Oro. The Age of Velázquez. Berlín y Múnich: Hirmer, pp. 71-79.

Martín González, Juan José (1974): Juan de Juni. Vida y obra. Madrid: Ministerio de Educación y Ciencia, Dirección General de Bellas Artes.

Palomino, Antonio (1947): El museo pictórico y escala óptica. Madrid: M. Aguilar Editor.

Peltier, Cyril (2006): "Sobre el recorrido formativo de Juan de Juni en Francia". En: Boletín del Museo Nacional de Escultura, 10, Valladolid, pp. 15-22.

Sánchez-Mesa Martín, Domingo (1992): “Escultura”. En: Sanchez-Mesa Martín, Domingo (coord.). Instituto Gómez Moreno. Granada: Fundación Rodríguez-Acosta, pp. 47-76.

Schotmüller, Frida (1913): Die italienischen und spanischen Bildwerke des Renaissance und des Barocks in Marmor, Ton, Holz und Stuck. Berlin: G. Reimer.

Schotmüller, Frida (1933): "Die italienischen und spanischen Bildwerke des Renaissance und des Barock”. En: Staatliche Museen zu Berlin: Die bildwerke des Kaiser-Friedrich-Museums. Band. 2. Die italienischen und spanischen Bildwerke des Renaissance und des Barock. Berlín: de Gruyter.

Staatliche Museen zu Berlin (1995): Dokumentation der Verluste: Gemäldegalerie Staatliche Museen zu Berlin. Berlin: Staatliche Museen zu Berlin-Preussischer Kulturbesitz.

Weniger, Matthias / Bucerius Kunst Forum / Gemäldegalerie Alte Meister / Szépmüvészeti Múzeum (eds.) (2005): Velázquez, Goya. Spanische Malerei aus deutschen Sammlungen. München y New York: Prestel.

Weniger, Matthias / Gemäldegalerie Alte Meister / Staatliche Kunstsammlungen Dresden (eds.) (2012): Spanische Malerei: Gemäldegalerie Alte Meister Staatliche Kunstsammlungen Dresden, Bestandskatalog spanische Malerei. München: Prestel.

Fecha de recepción: 15-II-2019

Fecha de aceptación: 30-V-2019 